\title{
Association between obesity and attention deficit hyperactivity disorder in children at a tertiary care outpatient setting: A comparative study
}

\author{
A Ellepola, GS Wijethunge, N Gunawardena
}

\section{Abstract \\ Background}

As the prevalence of childhood overweight and obesity increases in developing countries, it is important to identify associated morbidity. Attention deficit hyperactivity disorder (ADHD) has been recently recognized as one such comorbidity in this group. The current study describes the prevalence of ADHD among obese and non-obese children attending outpatient clinics at Lady Ridgeway Hospital (LRH), Sri Lanka.

\section{Aims}

The main focus of this study was to explore the association between ADHD and obesity in Sri Lankan children.

\section{Methodology}

This was a comparative cross sectional study of 209 children aged 6-12 years attending the outpatient department, and the outpatient clinic for obese children at Lady Ridgeway Hospital for Children, Colombo. Participant height and weight was measured and body mass index (BMI) was calculated. Obesity was defined as a BMI of more than 95th centile as per the reference charts. Demographic data was collected using a prepared format and assessment of ADHD was carried out based on DSM IV criteria using the K-SADS PL.

\section{Results}

The prevalence of ADHD among obese participants was $17.1 \%(n=18)$, compared to $5.7 \%(n=6)$ among the non-obese, and this difference was statistically significant. The combined type ADHD was the most common sub type, followed by the predominantly hyperactive-impulsive. There was a male preponderance with regards to the diagnosis of ADHD.

\section{Conclusions}

This study shows that the rate of ADHD is higher among children with obesity, compared to the non-obese. Reasons behind this co-morbidity are unknown. If replicated in future studies, these findings will have important implications in the prevention and management of ADHD in this population group.

Key words: ADHD, children, obesity

SL J Psychiatry 2020; 11(1): 45-51

\section{Background}

Overweight and obesity are defined as abnormal or excessive fat accumulation that presents a risk to health. A person with a body mass index (BMI) of 30 or more is generally considered obese (1). A person with a BMI equal to or more than 25 is considered overweight (1). Overweight and obesity are major risk factors for a number of chronic diseases (1).

Attention deficit hyperactivity disorder (ADHD) is a psychiatric disorder with many comorbidities (2). International studies report that the prevalence of ADHD among children aged 4-17 years increased from 7.8\% to 9.5\% during the period 2003-2007, representing a 21.8\% increase in patient numbers (3). ADHD is associated with lower levels of education and employment status (4). A Sri Lankan study conducted among 37 children attending the Child guidance Clinic at Lady Ridgeway Hospital for Children (LRH) reported a male preponderance of ADHD, with a mean age was 6.5 years (5). Perera et al. in their study of 34 children aged 3-10 years attending an ENT service in a tertiary care children's hospital with selfinserted foreign bodies, reported that $14.3 \%$ of the children had ADHD (6). 
Several studies have reported ADHD to be associated with obesity, signs of over-nutrition, higher body mass index or higher value of fat (7-9). Previous hypotheses of a possible lower rate of obesity in children with ADHD due to their increased activity has been contradicted by more recent research $(7,10)$.

Treatment of ADHD in the subset of children with obesity and ADHD may improve symptoms of both conditions. Thus, in addition to screening for addiction and binge eating in the obese population, children with obesity should also be evaluated for ADHD (11). Treatment with methylphenidate has been reported to cause an average decrease of BMI to $21.8 \mathrm{~kg} / \mathrm{m}^{2}$ (BMI-SDS 2.8) within 24 months (12). However, the association between childhood obesity and ADHD has not adequately studied in Sri Lanka.

Children with obesity are assessed and managed in a well-attended outpatient clinic at Lady Ridgeway Hospital for Children, Colombo, Sri Lanka (LRH). A psychiatric assessment is not routinely conducted at this clinic. Clients attending this clinic are likely to benefit from a psychiatric assessment and management if needed, particularly if there is a high risk of ADHD in this population.

The overall aim of this study was to determine the association between obesity and ADHD in an outpatient setting, at Lady Ridgeway Hospital for Children, Sri Lanka. The specific objectives were to describe the demographic characteristics of obese and non-obese children attending the outpatient clinic of LRH, to estimate the prevalence of ADHD in this population, and to determine whether ADHD is associated with obesity among children.

\section{Methods}

This was a cross sectional comparative study among two groups of children attending LRH. The study group comprised children with obesity, attending the obesity clinic of LRH, and the comparison group comprised nonobese children attending the outpatient department of the same hospital. For the purpose of the study, obesity was defined by a BMI of more than $95^{\text {th }}$ centile as per the reference charts used in Sri Lanka. Non-obesity in the comparison group was defined as a BMI between $3^{\text {rd }}$ and $95^{\text {th }}$ centile in the reference charts.

Children with obesity secondary to other conditions (for example secondary to Cushing syndrome), children with a known psychiatric disorder, mental retardation, pervasive developmental disorder, or any chronic medical or surgical conditions, as well as children on long term medication, were excluded, both from the study and comparison groups.

\section{Procedure}

Participants for the study were selected by convenient sampling method. Children aged 6-12 years attending the obesity clinic, who met inclusion criteria, were recruited to the study group in a consecutive manner. Height and weight were measured in each child by the principal investigator (AE) using the same measuring device, and BMI was calculated.

The first ten children from either gender, aged 6-12 years who attended the out-patient department, LRH every morning during the the study period were selected as the comparison group. Height, weight and BMI of each child were assessed in the same way for the study group. The required sample size for each group was calculated to be 101 .

ADHD was assessed by interview, using the schedule for Affective Disorders and Schizophrenia for School Aged Children (6-18 Years), or Kiddie-SADS - Present and Lifetime Version (K-SADS-PL), based on DSM IV criteria $(13,14)$. The tool was piloted prior to use in the study - probes of the screening questionnaire were translated to Sinhalese. The tool was translated and back translated between English and Sinhalese, by two doctors, each working independently. The English translation was compared with the original K-SADS PL and revisions were made to the Sinhala translation as required. The translated tool was then pre-tested in the local language prior to use. The Sinhalese version of the tool was administered among 10 children at the Child Guidance Clinic, LRH, and the results were compared with the clinical diagnosis of ADHD given by a consultant child and adolescent psychiatrist, who was blinded to the outcome of the K-SADS-PL scale. No false positives or negatives were detected during the pilot study and three out of the 10 children in the pilot study were diagnosed to have ADHD.

Children were clinically assessed for symptoms of pervasive developmental disorder and if a child showed features suggestive of the disorder he/she was referred to the Child guidance clinic for further evaluation. The TONI 3 test was used to assess nonverbal intelligence. It is a single-scale test, comprised of a series of diagrams that measures performance on a single factor associated with nonverbal problem solving capability.

Demographic data was collected using an intervieweradministered questionnaire. An analogue professional scale and a measuring tape was used to measure the height respectively.

\section{Ethical considerations}

Ethics clearance for the study was granted by the Ethics Review Committee of Lady Ridgeway Hospital for Children. Informed written consent was obtained from 
the adult caretaker of the child, prior to inclusion in the study. Prior to starting the study, approval of the consultant pediatrician in-charge of the obesity clinic was obtained to conduct the research. Consent to use the research tool was obtained from Prof. Joan Kaufman, the principal author of K-SADS-PL.

All children and adolescents found to have ADHD and/ or other mental health issues were referred to Specialized Child and Adolescent Mental Health Clinic, LRH for further assessment and treatment with the consent of caretakers of children/ adolescents. The management plan was discussed with children and their caretakers prior to referral.

\section{Analysis}

Data were analysed using SPSS 15 for Windows. Significance was set at $\alpha=0.05$. Analysis of variance was applied to means of age, sex, race, religion and social level. The independent t-test was used to compare the means of variables. Chi-square test was used to determine significance of differences among subject groups and BMI categories. Distributions of BMI categories according to ADHD status were compared using $\chi^{2}$ statistics. The odds of the occurrence of ADHD in children with and without obesity was compared.

\section{Results}

Hundred and five obese and 104 non-obese children and adolescents within the age range of 6 to 12 years were studied (Table 1). The response rate for both obese and non-obese children was $100 \%$ respectively.

While there was no significant difference between distribution of gender and sex between two groups, the monthly income of the family was significantly higher in the study group with obesity $(\mathrm{p}=0.021)$.

Clinical characteristcs of the study participants including complications during pregnancy among mothers, developmental milestones, immunization, TONI 3 score and ADHD status of children are summarized in Table 2. Only a minority of the mothers of children and adolescents included in the study reported pregnancy or labor related complications. The TONI 3 scores indicated average intelligence in a majority of the children and adolescents from both categories.

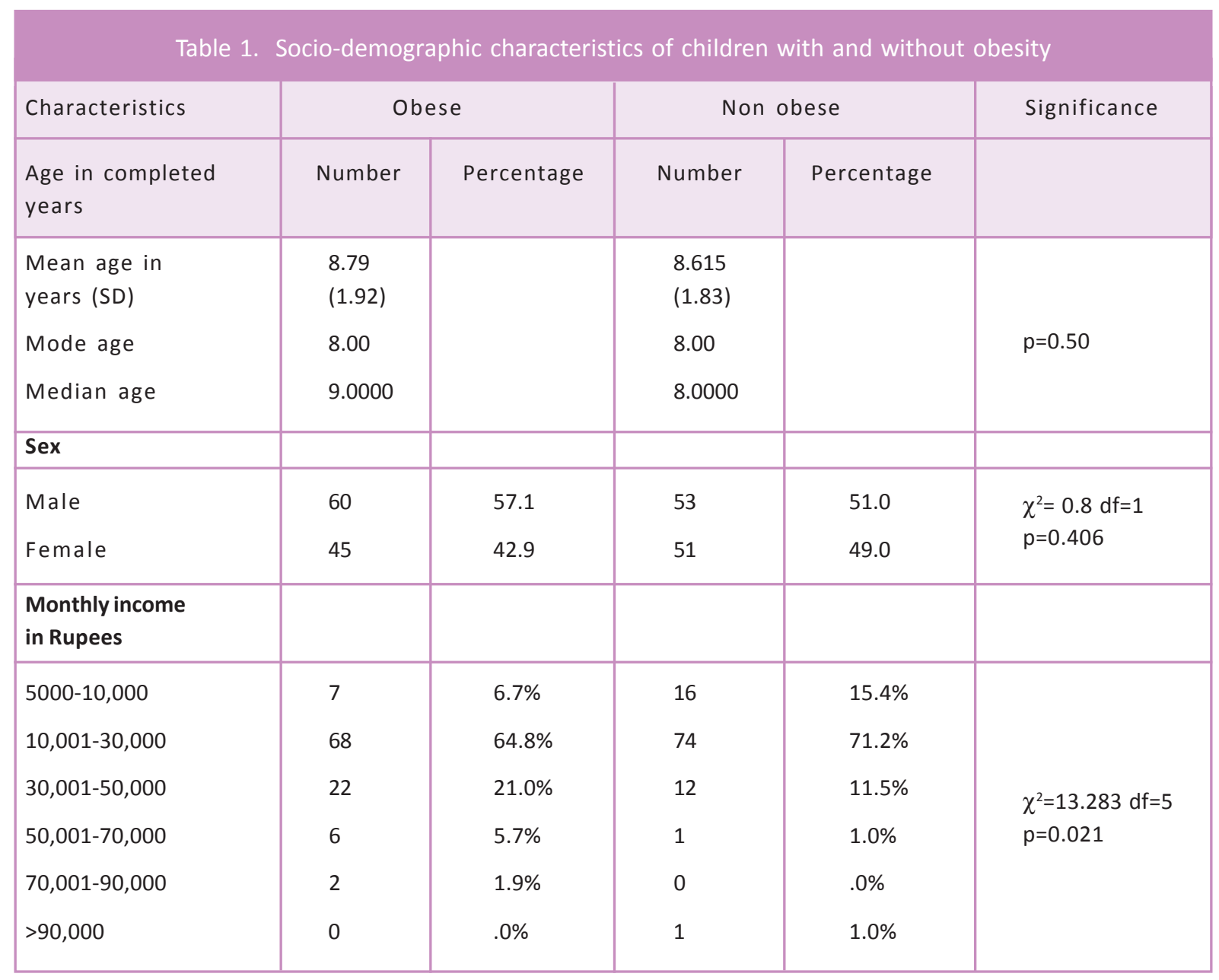


The prevalence of ADHD among the whole study population (obese and non-obese) was estimated to be $11.48 \%$ (24 children). Overall in the whole study population, ADHD was more common among males $(62.5 \%, \mathrm{n}=15)$ compared to females $(37.5 \%, \mathrm{n}=9)$.

The combined type of ADHD was the most common sub category of ADHD found among the whole study population (62.5\%, 15 children). The predominantly inattentive type of ADHD was present in 3 children (12.5\%), and 6 (25\%) children had predominantly hyperactive-impulsive type of ADHD.

The proportion of ADHD among children with obesity was $17.15 \%(n=18)$, compared to $5.7 \%(n=6)$ among the non-obese (Table 2). There was a statistically significant difference of ADHD prevalence between obese and non- obese children ( $p=0.010)$. The combined type ADHD was found in $10.47 \%(n=11)$ of obese and $3.8 \%(n=4)$ nonobese children, while $3.8 \%(n=4)$ obese and $1.9 \%(n=2)$ non-obese children had predominantly hyperactiveimpulsive type of ADHD. None of the non-obese children were affected by predominantly inattentive type of ADHD, but $2.85 \%(n=3)$ of obese children had the predominantly inattentive type of ADHD.

A majority of children with obesity started to show ADHD symptoms at an earlier age (2 to 5 years), compared to non-obese children. Obese children were found to have ADHD for a longer duration, compared to non-obese children (55.55\% of those with obesity had experienced ADHD for 4-6 years, compared to $50.0 \%$ of non obese children having suffered from ADHD for 2-3 years).

Table 2. Complications during pregnancy among mothers, developmental milestones, immunization, TONI 3 score and ADHD status of children

\begin{tabular}{|c|c|c|c|c|c|}
\hline Characteristics & \multicolumn{2}{|c|}{ Obese } & \multicolumn{2}{|c|}{ Non obese } & \multirow[t]{2}{*}{ Significance } \\
\hline $\begin{array}{l}\text { Complications } \\
\text { in pregnancy }\end{array}$ & Number & Percentage & Number & Percentage & \\
\hline $\begin{array}{l}\text { Yes } \\
\text { No }\end{array}$ & $\begin{array}{l}10 \\
95\end{array}$ & $\begin{array}{l}9.5 \% \\
90.5 \%\end{array}$ & $\begin{array}{l}4 \\
100\end{array}$ & $\begin{array}{l}3.8 \% \\
96.2 \%\end{array}$ & $\begin{array}{l}\chi^{2}=2.695 \mathrm{df}=1 \\
p=0.101\end{array}$ \\
\hline \multicolumn{6}{|l|}{$\begin{array}{l}\text { Developmental } \\
\text { milestones }\end{array}$} \\
\hline $\begin{array}{l}\text { Normal } \\
\text { Abnormal }\end{array}$ & $\begin{array}{l}99 \\
6\end{array}$ & $\begin{array}{l}94.3 \% \\
5.7 \%\end{array}$ & $\begin{array}{l}99 \\
5\end{array}$ & $\begin{array}{l}95.2 \% \\
4.8 \%\end{array}$ & $\begin{array}{l}\chi^{2}=0.086 \mathrm{df}=1 \\
p=0.769\end{array}$ \\
\hline \multicolumn{6}{|l|}{ Immunization } \\
\hline $\begin{array}{l}\text { Complete } \\
\text { Incomplete }\end{array}$ & $\begin{array}{l}103 \\
2\end{array}$ & $\begin{array}{l}98.1 \% \\
1.9 \%\end{array}$ & $\begin{array}{l}101 \\
3\end{array}$ & $\begin{array}{l}97.1 \% \\
2.9 \%\end{array}$ & $\begin{array}{l}\chi^{2}=0.215 \mathrm{df}=1 \\
p=0.643\end{array}$ \\
\hline \multicolumn{6}{|l|}{ TONI 3 Scores } \\
\hline $\begin{array}{l}\text { Superior } \\
\text { Above average } \\
\text { Average } \\
\text { Below average }\end{array}$ & $\begin{array}{l}1 \\
1 \\
88 \\
15\end{array}$ & $\begin{array}{l}1.0 \% \\
1.0 \% \\
83.8 \% \\
14.3 \%\end{array}$ & $\begin{array}{l}0 \\
0 \\
94 \\
10\end{array}$ & $\begin{array}{l}.0 \% \\
.0 \% \\
90.4 \% \\
9.6 \%\end{array}$ & $\begin{array}{l}\chi^{2}=3.193 \mathrm{df}=3 \\
p=0.363\end{array}$ \\
\hline \multicolumn{6}{|l|}{ ADHD Status } \\
\hline $\begin{array}{l}\text { Yes } \\
\text { No }\end{array}$ & $\begin{array}{l}18 \\
87\end{array}$ & $\begin{array}{l}17.15 \% \\
82.85 \%\end{array}$ & $\begin{array}{l}6 \\
98\end{array}$ & $\begin{array}{l}5.7 \% \\
94.3 \%\end{array}$ & $\begin{array}{l}\chi^{2}=6.649 \mathrm{df}=1 \\
p=0.010\end{array}$ \\
\hline & 105 & $100 \%$ & 104 & $100 \%$ & \\
\hline
\end{tabular}




\section{Discussion}

Attention deficit hyperactivity disorder (ADHD) is a common childhood disorder, which may negatively impact the development of an individual (15). In the past it was thought that ADHD was associated with a lower risk of obesity, but this view has been recently contradicted by more recent evidence (16). Recent work suggests an association between obesity and ADHD, though the number of studies are not many, and sample size and heterogeneous methodology limits findings (8). A systematic review of the literature conducted in 2008 suggested that obese patients referred to obesity clinics might present with a higher than expected prevalence of $\operatorname{ADHD}(17,18)$. To the best of our knowledge, this topic has not been studied previously in a Sri Lankan setting.

The prevalence of ADHD among non-obese children in the present study (5.7\%) was similar to the worldwide pooled prevalence of ADHD (5.29\%) (19). The findings of this study indicate that children with obesity have a statistically higher prevalence of ADHD when compared with non-obese children $(\mathrm{p}=0.01)$. This finding is in accordance with previous research that has linked overweight/ obesity and $\operatorname{ADHD}(8,17,18,20-22)$.

However, not all evidence favours this association. A research involving 56 overweight children and 53 normal weight children aged 10-18 years conducted in Belgium in 2007 showed more impulsivity, hyperactivity and inattention symptoms particularly in overweight boys, but did not demonstrate a higher prevalence of ADHD among children with overweight and obesity when compared to children of normal weight (23). The small number of study units included in the study may have affected the findings. A larger general population survey conducted among 9-16 year old children and adolescents in Netherlands in 2003 also concluded that the diagnosis of ADHD was not associated with any of the obesity trajectories (24).

This male preponderance of ADHD reported in the present study is consistent with previous studies done in Sri Lanka and elsewhere $(5,19,25)$. Families of obese children had a significantly higher monthly income when compared to that of non-obese children. This is in contrast to previous studies showing an association between obesity and low-income (26).

The exact mechanism for the association between obesity and ADHD is not known, but eating patterns, life style and caloric intake of ADHD individuals have been suggested as possible associated factors. Children and adolescents with ADHD who have not been medicated are reported to be more at risk of overweight and obesity when compared to medicated children (7). Impulsivity, lack of concentration and distractibility in ADHD could be contributory factors for poor meal planning and obesity $(8,9,18,27,28)$. It is postulated that impulsivity and inattention can lead to nourishment issues and vice versa. The direction of association is not clear (18). It is not possible to comment on the direction of association with the results available from this study, as the study design does not give information about the temporal association of the conditions. Another hypothesis is that ADHD and eating disorders share common neurobiological factors (29). Overall, the association between obesity and ADHD has significant clinical and therapeutic implications.

\section{Limitations}

This study focused on children aged 6-12 years. Inclusion of children below 6 years, and adolescents would have yielded results applicable to a wider group of children and adolescents. Generalization of the results to Sri Lankan population could be difficult, as the study was done in a clinical set-up at a tertiary care children's hospital in Colombo. In addition, the study was unable to comment on the direction of association between obesity and ADHD.

\section{Conclusions}

The results of this study indicate a higher prevalence of ADHD among children with obesity compared to nonobese children. This finding highlights the importance of including a child psychiatry component in the management of childhood obesity. It is crucial to identify and manage the symptoms and signs of ADHD in obese children early in order treat and improve their quality of life.

The nature and direction of the associations between ADHD and obesity is still not clearly understood. Future larger studies are needed to explore this area in more depth. Better understanding of this topic will help to reduce the suffering, disability and economic cost related to ADHD and obesity. Inclusion of more diverse and non-clinical populations of obese individuals will give more definitive answers to this important question.

\section{Conflicts of interest}

None declared.

\section{Funding: None}

\section{Acknowledgments}

Authors of the study acknowledge the support extended by Prof. Pujitha Wickramesinghe (Professor in Pediatrics, University of Colombo) in studying the cohort of obese children. The authors also gratefully acknowledge staff members and patients at the outpatient department and room 22 of Lady Ridgeway Hospital for Children, who helped enormously to conduct this research. 
A Ellepola, Consultant Psychiatrist, Teaching hospital, Anuradhapura, Sri Lanka

GS Wijethunge, Consultant Child Psychiatrist, Lady Ridgeway Hospital for Children, Colombo, Sri Lanka

N Gunawardena, Professor in Community Medicine, University of Colombo, Sri Lanka

Corresponding author: A Ellepola

Email: anu.ellepola@gmail.com

http://orcid.org/0000-0001-9699-2777

\section{References}

1. De Onis M, Lobstaein L. Defining obesity risk status in the general childhood population: Which cut-offs should we use? Int J Pediatr Obes 2010; 5: 458-60.

2. Quinn PO.Attention-deficit/hyperactivity disorder and its comorbidities in women and girls: an evolving picture. Curr Psychiatry Rep 2008; 10: 419-23.

3. Blumberg SJ, Foster EB, Frasier AM, et al. Design and operation of the National Survey of Children's Health. Vital Health Stat 1 2012; 55:1-149.

4. Faraone SV, Biederman J. What is the prevalence of adult ADHD? Results of a population screen of 966 adults. J Atten Disord 2005; 9: 384-91.

5. Kariyawasam SH, Koralagama A, Jayawardane P, Karunathilake B, Perera V, Perera H. A descriptive study of attention deficit hyperactivity disorder (ADHD) at Lady Ridgeway Hospital for Children, Colombo. SL J Child Health 2002; 31: 109-14.

6. Perera H, Fernando SM, Yasawardena ADKSN, Karunaratne I. Prevalence of attention deficit hyperactivity disorder (ADHD) in children presenting with self-inserted nasal and aural foreign bodies. Int J Pediatric Otorhinolaryngol 2009; 73: 1362-4.

7. Altfas JR. Prevalence of attention deficit/hyperactivity disorder among adults in obesity treatment. BMC psychiatry. 2002; 2: 9.

8. Molly E, Waring MA, Lapane KL. Overweight in children and adolescents in relation to attention-deficit/ hyperactivity disorder: results from a national sample. Paediatrics. 2008; 122: e1-6.

9. Ptacek R, Kuzelova H, Papezova H, Stepankova T. Attention deficit hyperactivity disorder and eating disorders. Prague Med Rep 2010; 111: 175-81.

10. Curtin C, Bandini LG, Perrin EC, Tybor DJ, Must A. Prevalence of overweight in children and adolescents with attention deficit hyperactivity disorder and autism spectrum disorders: a chart review. BMC Pediatr 2005; 21: 48.
11. Yang R. ADHD and obesity. CMAJ 2010; 182: 482.

12. Albayrak O, Albrecht B, Scherag S, Barth N, Hinney A, Hebebrand J. Successful methylphenidate treatment of early onset extreme obesity in a child with a melanocortin4 receptor gene mutation and attention deficit/hyperactivity disorder. Eur J Pharmacol 2011; 660: 165-70.

13. Birmaher B, Ehmann M, Axelson DA, et al. Schedule for Affective Disorders and Schizophrenia for School-Age Children (K-SADS-PL) for the Assessment of Preschool Children - A Preliminary Psychometric Study. J Psychiatr Res 2009; 43: 680-6.

14. Kaufman J, Birmaher B, Brent D, et al. Schedule for affective disorders and schizophrenia for school-age children - present and lifetime version (K-SADS-PL): Initial reliability and validity data. J Am Acad Child Adolesc 1997; 36: 980-7.

15. Wolraich ML, Wibbelsman CJ, Brown TE, et al. Attentiondeficit/hyperactivity disorder among adolescents: A Review of the diagnosis, treatment, and clinical implications. Pediatrics 2005; 115; 1734-46.

16. Schwartz BS, Bailey-Davis L, Bandeen-Roche K, et al. Attention deficit disorder, stimulant use, and childhood body mass index trajectory. Pediatrics 2014; 133: 668-76.

17. Cortese S, Angriman M, Maffeis C, et al. Attention-deficit/ hyperactivity disorder (ADHD) and obesity: a systematic review of the literature. Crit Rev Food Sci Nutr 2008; 48: 524-37.

18. Cortese S, Penalver MC. Comorbidity between ADHD and obesity: exploring shared mechanisms and clinical implications. Postgrad Med 2010; 122(5): 88-96.

19. Polanczyk G, De Lima MS, Horta BL, Biederman J, Rohde LA. The Worldwide Prevalence of ADHD: A Systematic Review and Meta regression Analysis. Am J Psychiatry. 2007; 164: 942-8.

20. Agranat-Meged AN, Deitcher C, Goldzweig G, Leibenson L, Stein M, Galili-Weisstub E. Childhood obesity and attention deficit/hyperactivity disorder: a newly described comorbidity in obese hospitalized children. Int $\mathrm{J}$ Eat Disord 2005; 37: 357-9.

21. Holtkamp K, Konrad K, Müller B, et al. Overweight and obesity in children with Attention-Deficit/ Hyperactivity Disorder. Int J Obes Relat Metab Disord 2004; 28: 685-9.

22. Erermis S, Cetin N, Tamar M, Bukusoglu N, Akdeniz F, Goksen D. Is obesity a risk factor for psychopathology among adolescents? Pediatr Int. 2004; 46: 296-301.

23. Braet C, Claus L, Verbeken S, Van Vlierberghe L. Impulsivity in overweight children. Eur Child Adolesc Psychiatry. 2007; 16(8): 473-83.

24. Mustillo S, Worthman C, Erkanli A, Keeler G, Angold A, Costello EJ. Obesity and psychiatric disorder: developmental trajectories. Pediatrics. 2003; 111: 851-9. 
25. Faraone SV, Sergeant J, Gillberg C, Biederman J. The worldwide prevalence of ADHD: is it an American condition? World Psychiatry. 2003; 2(2): 104-113

26. Rogers R, Eagle TF, et al. The Relationship between Childhood Obesity, Low Socioeconomic Status, and Race/ Ethnicity: Lessons from Massachusetts. Child Obes. 2015; 11(6): 691-695.

27. Wang Y, Lobstein T. Worldwide trends in childhood overweight and obesity. Int J Paediatr Obes. 2006; 1: $11-25$
28. Malmberg K, Edbom, T, Wargelius HL, Larsson JO. Psychiatric problems associated with subthreshold ADHD and disruptive behaviour diagnoses in teenagers. Acta Paediatrica. 2011; 100(11): 1468-75.

29. Agranat-Meged A, Ghanadri Y, Eisenberg I, Ben Neriah Z, Kieselstein-Gross E, Mitrani-Rosenbaum S. Attention deficit hyperactivity disorder in obese melanocortin-4receptor (MC4R) deficient subjects: a newly described expression of MC4R deficiency. Am J Med Genet B Neuropsychiatr Genet. 2008; 147B(8): 1547-53. 